Board of Governors of the Federal Reserve System

International Finance Discussion Papers

Number 665

April 2000

\title{
MONETARY POLICY INDEPENDENCE IN THE ERM: WAS THERE ANY?
}

\author{
Hali J. Edison and Ronald MacDonald
}

NOTE: International Finance Discussion Papers are preliminary materials circulated to stimulate discussion and critical comment. References in publications to International Finance Discussion Papers (other than an acknowledgment that the writer has had access to unpublished material) should be cleared with the author or authors. Recent IFDPs are available on the Web at www.bog.frb.fed.us. 


\title{
MONETARY POLICY INDEPENDENCE IN THE ERM: WAS THERE ANY?
}

\author{
Hali J. Edison and Ronald MacDonald*
}

\begin{abstract}
Recently proposals for introducing greater exchange rate fixity into the behavior of key exchange rates have become fashionable. One proposal, for example, suggests that a target zone arrangement for the dollar, mark and yen would represent a desirable reform of the international monetary system. The question we seek to address in this paper is how much monetary independence is likely to be conferred on a country participating in such an arrangement. Recent research for the Classical gold standard has suggested that even with a rigidly fixed exchange rate system there is still some scope for monetary independence. Here we examine the extent of monetary independence conferred by a target zone using data from the recent ERM experience. Amongst our findings is the result that countries which had a credible commitment to the target zone had more independence in the operation of their monetary policy than countries with a lesser commitment. It turns out that the monetary independence for a credible participant in a target zone arrangement is longer than that conferred by participation in a regime of rigidly fixed exchange rates, such as the Classical gold standard.
\end{abstract}

JEL Classifications: F31, F32, F33.

Keywords: Interest Rate Linkages; Monetary Independence

* The first author is a senior economist in the Division of International Finance, Board of Governors of the Federal Reserve System, Washington, D.C. 20551 U.S.A. and the second author is a Professor of Economics at the University of Strathclyde, Glasgow G41 4PZ UK. The authors may be reached on the Internet at hali.edison@frb.gov and r.r.macdonald@strath.ac.uk , respectively. The views in this paper are solely the responsibility of the authors and should not be interpreted as reflecting the views of the Board of Governors of the Federal Reserve System or any other person associated with the Federal Reserve System. 


\section{Introduction}

The aim of this paper is to analyze interest rate linkages for a number of countries who participated in the exchange rate mechanism (ERM) of the European monetary system (EMS). Although such linkages have been examined by others, the focus of previous work differs to that considered here. ${ }^{1}$ In particular, we seek to evaluate how much monetary independence participation in the ERM conferred on a country, rather than focussing on the symmetric/ asymmetric properties of an EMS participant's interest rate policies. For example, Svensson (1994) has demonstrated that if a target zone system, such as the ERM, is credible then it will facilitate some monetary independence, particularly at the short end of the maturity spectrum. Most, if not all, fixed exchange rate system may be modeled as a target zone mechanism. Officer (1995) and Hallwood, MacDonald and Marsh (1995), for example, have demonstrated that the classical gold standard represented a highly credible target zone system and Bordo and MacDonald (1997) have established that this conferred monetary independence of up to one year on participating countries. Although a number of papers have examined the credibility of the ERM experience (see, for example, Rose and Svensson (1994)) none, to our knowledge, has examined the issue of policy independence for the ERM.

It is now widely accepted that for much of its operation the ERM did not represent a credible target zone. However, for particular time periods some countries monetary policy did appear to be highly credible (for example the Netherlands towards the end of the original ERM experiment) and also countries which lacked full credibility could still be distinguished in terms of differing degrees of non-credibility. How then did the general lack of absolute credibility and,

\footnotetext{
${ }^{1}$ For example, previous research on interest rate interactions within the ERM has focussed on issues relating to the symmetric or asymmetric operation of the system; see, inter alia, De Grauwe (1989), Weber (1990), Von Hagen and Fratianni (1990) and Edison and Kole (1995).
} 
more specifically, the differing degrees of relative credibility show up in interest rate policy? Did it give some countries more independence than others, or were all countries equally plagued by the general lack of (absolute) credibility? In this paper we examine these kinds of questions using daily interest rate data, for the period March 1979 to May 1996, for 6 ERM countries against Germany and the US. Additionally, two control countries - Canada and Japan - are used to check the sensitivity of our results. Of course the existence of a full blown monetary union in Europe since 1999 means that there is now only a single interest rate policy across Europe. However, we believe it is still of interest to examine the precursor to this single interest rate policy in order to see how the rules of the game have changed over time. This is of special interest given that proposals for greater fixity for the tri-polar grouping of dollar, mark and yen seems to be back on the political agenda again. Bordo and MacDonald (1997) have assessed the monetary independence conferred by a rigidly fixed regime (the Classical gold standard) and our objective here is to assess how much monetary independence a system of fixed but adjustable exchange rates gives. To our knowledge this issue has not been addressed before in the literature.

The outline of the remainder of this paper is as follows. In Section 2 we present a brief motivational framework for our econometric modeling. In Section 3 our econometric methods are detailed. Our data sources are discussed in section 4 and the econometric results are contained in Section 5. Section 6 concludes.

\section{Motivation}

A number of empirical studies on the time series behavior of ERM exchange rates have used a target zone framework (see, for example, Rose and Svensson (1994) and Anthony and 
MacDonald (1998)). A key assumption in this framework is the condition of uncovered interest rate parity (UIP), which is defined as:

$$
i_{t}=i_{t}^{*}+E_{t} \Delta s_{t+k},
$$

where $i_{t}$ denotes the domestic interest rate, $i_{t}{ }^{*}$ denotes the foreign rate, $s_{t}$ is the spot exchange rate, $E_{t}$ is the conditional expectations operator and $s_{t}$ is transformed logarithmically. It is this relationship which is the focus of our study. More specifically, Svensson (1994) has argued that in a credible target zone there should be some 'short-run' scope for the home short interest rate to deviate from the comparable foreign rate, but in the longer term such independence vanishes. By examining interest rate relationships for the ERM countries we hope to capture this feature of the Svensson model. For example, if the home and German (GY) short term interest rates are individually non-stationary, or I(1), then for them not to deviate persistently from each other in the longer term they should produce a cointegrating relationship of the form first proposed by Engle and Granger (1987). ${ }^{2}$ That is, in the context of an estimated version of equation (2) $\beta_{0}$ should differ insignificantly from zero, $\beta_{1}$ should be insignificantly different from unity and the error process, $v_{t}$, is expected to be stationary, or $\mathrm{I}(0)$ :

$$
i_{t}=\beta_{0}+\beta_{1} i_{t}^{G Y}+v_{t}
$$

Essentially the existence of a cointegrating relationship amongst the interest rates represents our base-line test. We discuss below the cointegration methods used to test for cointegration.

The expected change in the exchange rate within the band does not appear in the cointegrating relationship since it is expected to be $\mathrm{I}(0)$ and will not affect the long-run result (in a cointegration sense). However, the non-zero expected change in the exchange rate will be

\footnotetext{
${ }^{2}$ As we demonstrate in Section 4, all of the interest rates considered in this paper are I(1) processes.
} 
captured in the short-run dynamic equations implied by (2). In particular, if the two interest rates defined in (2) are cointegrated, and if the constraints $\beta_{0}=0$ and $\beta_{l}=1$ are satisfied, then the Granger Representation theorem implies that a dynamic error correction representation of the following form must exist:

$$
\begin{aligned}
& \Delta i_{t}=-\alpha_{0}\left(i_{t-1}-i_{t-1}^{G Y}\right)+\sum_{i=1}^{p} \kappa_{i} \Delta i_{t-i}+\sum_{i=1}^{p} \gamma_{i} \Delta i_{t-i}^{G Y}, \\
& \Delta i_{t}^{G Y}=+\alpha_{1}\left(i_{t-1}-i_{t-1}^{G Y}\right)+\sum_{i=1}^{p} \omega_{i} \Delta i_{t-i}+\sum_{i=1}^{p} \delta_{i} \Delta i_{t-i}^{G Y},
\end{aligned}
$$

where the first term on the right-hand-side of each equation represents the error correction mechanism (ECM) recovered from the cointegration tests on (2). The significance and magnitude of this coefficient will be informative with respect to which of the interest rates adjusts in response to a disturbance to the levels terms and how rapidly adjustment occurs. It should enter significantly negative in the first equation, to the extent that the home interest rate is adjusting, and significantly positive in the second, to the extent that the foreign rate is adjusting (this simply follows from the way we have defined the ECM term in both equations as the spread between the 'home' and German rate). Additionally, the magnitude of the $\alpha$ coefficients indicate how long a non-zero expected change in the exchange rate persists and therefore how much monetary independence there actually is. For example, assume $\alpha_{1}$ is insignificantly different from zero, and therefore the DM rate is weakly exogenous. If the estimated value of $\alpha_{0}$ is insignificantly different from unity then this would suggest that adjustment occurs within the period (a day in our context) and therefore there would be no policy independence. A number close to zero for $\alpha_{0}$ (although significantly different from zero) would imply hardly any 
adjustment and would therefore suggest considerable monetary independence. At the end of the day, the extent of monetary independence is an empirical issue, although in a highly credible target zone it is likely to be limited.

Given that the main focus of our study is the behavior of the interest rates of countries participating in the ERM, it seems natural to take the German-based rate as the 'foreign' interest rate. However, previous studies (see, for example, Edison and Kole (1995)) have demonstrated the need to additionally include a comparable US interest rate into this system. Whether the US rate appears explicitly in the long-run relationships, or simply in the short-run dynamics, is something we actually test in the next section. However, assuming for the time being that it appears in the long-run relationship we have a system comprising the home short interest rate, $i_{t}$, a comparable short German rate, $i_{t}^{G Y}$ and the US rate, $i_{t}^{U S}$. We refer to the bivariate model, consisting of the 'home' and German rate, as system 1 and the trivariate model, consisting of the 'home', German and US rates, as system 2. With two foreign rates the dynamic error correction representation for the home country becomes:

$$
\Delta i_{t}=-\alpha_{0}\left(i-i^{G Y}-i^{U S}\right)_{t-1}+\sum_{i=1}^{p} \kappa_{i} \Delta i_{t-i}+\sum_{i=1}^{p} \gamma_{i} \Delta i_{t-i}^{G Y}+\sum_{i=1}^{p} \mu_{i} \Delta i_{t-i}^{U S},
$$

where we have assumed that the cointegrating vector is of the form $[1,-1,-1]$ (these restrictions are actually tested in the empirical section). Of course, associated with (4) will be an additional two dynamic equations for the change in the US and German short rates. Again, as in the bivariate model, the $\alpha_{0}$ coefficient will be informative about the extent of policy independence. The econometric methods used to estimate equations (3) and (4) also give information on which 
of the two foreign rates is most important in 'driving' or pushing the system to equilibrium. We now turn to a brief discussion of our econometric methods.

\section{Econometric Methods}

We propose modeling the interest rate systems using the methods of Johansen (1995).

Johansen's procedure, which adopts a parametric correction to account for serial correlation and simultaneous equation bias (that may contaminate single equation estimates derived from a twostep estimator - see, for example, Campbell and Perron (1991)), faciliates testing for the number of significant cointegrating vectors and implementing testable restrictions on the vectors. The method is based on the following VAR structure. Define an (nx1) vector $x_{\mathrm{t}}$ which contains the $\mathrm{n}$ variables of interest (in terms of system 2 it simply contains three interest rates) and assume it has a vector autoregressive representation of the form:

$$
x_{t}=\eta+\sum_{i=1}^{p} \Pi_{i} x_{t-i}+\varepsilon_{t}
$$

where $\eta$ is an $(\mathrm{nx} 1)$ vector of deterministic variables, and $\varepsilon_{\mathrm{t}}$ is an $(\mathrm{nx} 1)$ vector of white noise disturbances, with mean zero and covariance matrix $\Xi$. Expression (5) may be reparameterised into the vector error correction mechanism (VECM) as:

$$
\Delta x_{t}=\eta+\sum_{i=1}^{p-1} \Phi_{i} \Delta x_{t-1}-\Pi x_{t-1}+\varepsilon_{t}
$$

where $\Delta$ denotes the first difference operator, $\Phi_{i}$ is an $(n x n)$ coefficient matrix (equal to $-\sum_{j=i+1}^{p} \Pi_{j}$,

$\Pi$ is an (nxn) matrix (equal to $\sum_{i=1}^{p-1} \Pi_{i}-I$ ) whose rank determines the number of cointegrating vectors. If $\Pi$ is either full rank, $n$, or zero rank $\Pi=0$, there will be no cointegrating vectors 
amongst the elements in the long-run relationship. If, however, $\Pi$ is of reduced rank, $r$ (where $r<n$ ), then there will exist (nxr) matrices $\alpha$ and $\beta$ such that $\Pi=\alpha \beta^{\prime}$, where $\beta$ is the matrix whose columns are the linearly independent cointegrating vectors and the $\alpha$ matrix is interpreted as the adjustment matrix, indicating the speed with which the system responds to last periods deviation from the equilibrium level. Hence the existence of the VECM model, relative to say a VAR in first differences, depends on the existence of cointegration.

We test for the existence of cointegration amongst the variables contained in $x_{\mathbf{t}}$ using Johansen's Trace test. ${ }^{3}$ The likelihood ratio, or Trace, test statistic for the hypothesis that there are at most $r$ distinct cointegrating vectors is:

$$
T R=T \sum_{i=r+1}^{N} \ln \left(1-\hat{\lambda}_{i}\right)
$$

where $\hat{\lambda}_{r+1}, \ldots ., \hat{\lambda}_{N}$ are the N-r smallest squared canonical correlations between $x_{\mathrm{t}-\mathrm{k}}$ and $\Delta x_{\mathrm{t}}$ series (where all of the variables entering $\mathbf{x}_{\mathrm{t}}$ are assumed I(1)), corrected for the effect of the lagged differences of the $x_{\mathrm{t}}$ process (for details of how to extract the $\lambda$ 's see Johansen (1988)). Johansen (1988) shows that (7) has a non-standard distribution under the null hypothesis. He does, however, provide approximate critical values for the statistic, generated by Monte Carlo methods (see also Osterwald-Lenum (1993)).

Johansen (1995) has further demonstrated that the VECM model in (5) has a vector moving average representation of the following form:

$$
x_{t}=C \sum_{i=1}^{t} \varepsilon_{i}+C \mu t+C^{*}(L)\left(\varepsilon_{t}+\mu\right)
$$

\footnotetext{
${ }^{3}$ We do not estimate Johansen's lMax statistic since it is known to be biased in the presence of non-normal errors (which are a feature of some of our systems) - see Cheung and Lai (1993).
} 
where

$$
C=\beta_{\perp}\left(\alpha_{\perp}^{\prime}\left(I-\sum_{1}^{k-1} \Gamma_{i}\right) \beta_{\perp}\right)^{-1} \alpha_{\perp}^{\prime}
$$

For our purposes the representation in $\left(5^{\prime}\right)$ is important because $\alpha \perp$ determines the vectors defining the space of the common stochastic trends and therefore should be informative about the key interest rates which drive the systems. The $\beta_{\perp}$ vector gives the loadings associated with $\alpha_{\perp}$ and which variables the common trends end up feeding into. Additionally, using (5') it is possible to calculate the impulse response of a shock to one variables and how it is transmitted over time within the system. Rather than reporting the impulses for a unitary change of $\varepsilon_{i t}$ we report only the final impact matrix, $\mathrm{C}$.

\section{Data Sources.}

The interest rates analyzed in this paper all have a three month maturity and were sourced from the Bank of International Settlements. We examine the rates for seven European countries - Belgium, Denmark, France, Germany, Italy, the Netherlands and the UK - and three control rates - the US, Canada and Japan. The sample period runs from January 1979 through to May 1996, and the observational frequency is daily. In Figure 1 we plot the co-movements of each of the ERM interest rates with both German and US rates, and the co-movements of the Canadian and Japanese rates are plotted relative to the US. For the ERM rates we note a number of general properties. First, there is considerable turbulence in the three rate combinations around the inception of the ERM, although turbulence in the 'own' rate is usually the most pronounced. This turbulence may be a reflection of the start-up of the ERM or the change in the operation of US monetary policy during this period. The rates then go through a period of relative tranquility 
until the demise of the ERM in the early 1990's when there is again marked turbulence, although not of the same magnitude as at the start of the sample. Interestingly, the UK, which was only a full member of the ERM for part of the sample, appears to have suffered higher own rate volatility throughout the sample than other European interest rates which were full participants in the ERM. As expected, perhaps, the correlation between Canadian and US interest rates is very close throughout the sample and, interestingly, the same volatility we observe in ERM rates in the late 1970's / early 1980's is also evident here. This would seem to suggest that the volatility in European rates for this period, noted above, is driven by changes in US monetary policy rather than turbulence associated with the ERM. The Japanese 3 month rate also has some of this early volatility although it is less pronounced than for any of the other interest rates and, in general, the Japanese rate exhibits much less volatility for the full sample.

\section{Econometric Results.}

\subsection{Cointegration Results}

The results from estimating bivariate interest rate systems for each of the European interest rates against Germany proved problematic, irrespective of including exchange rate realignment dummies or not. ${ }^{4}$ In particular, the evidence for cointegration was weak, the residuals were not well-behaved and they exhibited clear evidence of autocorrelation and heteroscedasticity. These results are not reported. However, we found that introducing the US rate into the bivariate pairings produced systems with clear evidence of cointegration and which contained non-autocorrelated residuals. We therefore focus on these trivariate systems here. The

\footnotetext{
${ }^{4}$ We experimented with a whole range of different dummies, including step dummies, corresponding to the time of an exchange rate realignment, and various 'moving window' dummies which were designed to capture turbulence both before and after a realignment.
} 
justification for including the US rate in these systems is that despite the deliberate attempts to converge on the German monetary policy during this period, US monetary policy still provided the central axis in terms of interest rate policy.

In each trivariate system the Schwartz criterion was used to determine the VAR lag length (although this was overridden in cases where serial correlation was still present with the chosen lag length). In Table 1a we present some residual diagnostics from each of the systems. The column headings contain the particular home country mnemonic for each system. More specifically, BM, DK, FE, IY, ND and UK represent Belgium, Denmark, France, Italy, the Netherlands and the United Kingdom, respectively, and a 3 indicates the relevant interest rate has a three month maturity. The rows labeled $\mathrm{LM}(1), \mathrm{LM}(4)$ and $\mathrm{NM}(6)$ are portmanteau statistics for residual correlation and normality. In particular, $\mathrm{LM}(1$ and 4$)$ are multivariate Godfrey (1988) LM-type statistics for first and fourth order autocorrelation, respectively, and $\mathrm{NM}(6)$ is a Doornik and Hansen (1994) multivariate normality test. Reported numbers are p-values and indicate, in general, an absence of serial correlation (i.e. $\mathrm{p}>0.05$ ), although there is some evidence of non-normality in all of the systems (i.e. $\mathrm{p}<0.05$ ). This non-normality remained irrespective of the inclusion of realignment dummies or not. However, since the source of the non-normality was kurtosis, rather than skewness, we do not regard it is a serious problem (i.e. Gonzalo (1994) has demonstrated that the kind of cointegration results reported in this paper are unaffected by excess kurtosis). Since, as we have indicated, the use of realignment dummies made no difference to any of our results, all of the results reported in this paper are for systems which do not feature realignment dummies. We believe that the unimportance of the realignment dummies 
probably reflects the fact that they are relatively small in number compared to the total number of observations: it is the average information contained in the latter which drives our results.

Table 1a. Pormanteau Residual Diagnostics for ERM systems.

\begin{tabular}{|c|c|c|c|c|c|c|}
\hline & Intere & e Syst & & & & \\
\hline Statistic & BM3 & DK3 & FE3 & IY3 & ND3 & UK3 \\
\hline $\mathrm{LM}(1)$ & 0.47 & 0.03 & 0.38 & 0.06 & 0.04 & 0.07 \\
\hline $\mathrm{LM}(4)$ & 0.72 & 0.11 & 0.16 & 0.02 & 0.08 & 0.47 \\
\hline $\operatorname{NM}(6)$ & 0.00 & 0.00 & 0.00 & 0.00 & 0.00 & 0.00 \\
\hline
\end{tabular}

Table $1 \mathrm{~b}$ contains a set of multivariate unit root tests, conditional on the rank of the VAR, discussed below. The null hypothesis is that the series in question is stationary and the test statistic has a $\chi^{2}$ distribution with one degree of freedom. The columns describe the interest rate systems. So, for example, BM3 describes the interest rate system for the Belgian interest rate (home) on the German three month rate (GY3) and the US three month rate (US3). The numbers in each cell are the estimated $\chi^{2}$ statistics for the stationarity of the home, GY3 and US3 rates in each system. 
Table 1b Multivariate Unit Root Tests.

\begin{tabular}{|l|l|l|l|l|l|l|}
\hline & \multicolumn{6}{|l|}{ Interest Rate System (conditional on a rank of one cointegrating vector) } \\
\hline & BM3 & DK3 & FE3 & IY3 & ND3 & UK3 \\
\hline Home & 8.42 & 6.71 & 31.54 & 31.20 & 33.13 & 5.99 \\
\hline GY3 & 5.99 & 4.70 & 6.76 & 7.05 & 33.52 & 8.21 \\
\hline US3 & 9.68 & 4.35 & 29.69 & 30.75 & 0.13 & 3.63 \\
\hline
\end{tabular}

Since the 5 per cent critical value for the statistics reported in Table $1 \mathrm{~b}$ is 3.84 , the null hypothesis of stationarity is clearly rejected in all cases except one. The exception is the US3 rate, which appears stationary in the ND3 equation. Since this variable is non-stationary in all other systems, it is likely that it is also non-stationary in the Netherlands system, despite the value of the test statistic (however, since it is legitimate to mix both $\mathrm{I}(1)$ and $\mathrm{I}(0)$ variables in the multivariate methods of Johansen, this issue is not critical).

In Table 2 we report the Trace test statistics for the numbers of cointegrating relationships in the trivariate ERM systems. Cheung and Lai (1993) have shown that the Johansen Trace test is robust to non-normality in the residuals and since, as we have seen, each of our systems does exhibit some non-normality we prefer to use this statistic rather than the $\lambda$ Max statistic which is known to be biased in the presence of non-normality. Using a $95 \%$ critical value we note that for all of the systems there is evidence of a single cointegrating vector (that is, the null hypothesis, $r=0$, is rejected in favor of the alternative $r \leq 1$ ). This confirms the point made above: the existence of the US interest rate in the data generating process is crucial in producing the cointegration result. Below we implement some hypothesis tests on these 
relationships to determine if any of the interest rates can be excluded from the long-run cointegrating space and, also, if any of the rates are weakly exogenous to the system and therefore may be driving (but not reacting to) the other rates.

Table 2. Numbers of Cointegrating Relationships in the Trivariate ERM Systems

\begin{tabular}{|l|l|l|l|l|l|l|l|}
\hline Trace & BM3 & DK3 & FE3 & IY3 & ND3 & UK3 & $95 \%$ \\
\hline $\mathrm{R}=0$ & 34.47 & 33.36 & 32.76 & 53.08 & 55.27 & 57.74 & 31.53 \\
\hline $\mathrm{R} \leq 1$ & 13.10 & 14.99 & 14.16 & 11.70 & 11.30 & 13.08 & 17.95 \\
\hline $\mathrm{r} \leq 2$ & 3.69 & 4.10 & 3.49 & 4.30 & 3.86 & 3.96 & 8.17 \\
\hline
\end{tabular}

In Table 3 the estimated values of the unrestricted cointegrating vectors (normalized on the 'home' or 'own' interest rate) and the associated alpha vectors (and associated t-ratios) are reported. These tables should be read in the following way. The row headings relate to the interest rate systems. So, for example, BM3 is the system comprising the Belgian, German and US rates. The columns below ' $\beta$ vector' contain the estimates of the cointegrating coefficients (normalized on the 'home' country), while the columns below ' $\alpha$ vector' contain estimates of the adjustment speeds. 
Table 3. Estimates of the Unrestricted $\beta$ and $\alpha$ Vectors

\begin{tabular}{|l|l|l|l|l|l|l|l|}
\hline & \multicolumn{3}{|c|}{$\beta$ Vector } & & \multicolumn{3}{c|}{$\alpha$ Vector } \\
\hline & Home & GY3 & US3 & Constant & Home & GY3 & US3 \\
\hline BM3 & 1 & -0.823 & -0.710 & 0.819 & $\begin{array}{l}-0.003 \\
(3.99)\end{array}$ & $\begin{array}{l}-0.001 \\
(1.77)\end{array}$ & $\begin{array}{l}0.001 \\
(1.19)\end{array}$ \\
\hline DK3 & 1 & -0.781 & -0.491 & 0.146 & $\begin{array}{l}-0.006 \\
(3.79)\end{array}$ & $\begin{array}{l}-0.000 \\
(0.24)\end{array}$ & $\begin{array}{l}0.001 \\
(1.61)\end{array}$ \\
\hline FE3 & 1 & -0.417 & -0.664 & -0.172 & $\begin{array}{l}-0.008 \\
(4.67)\end{array}$ & $\begin{array}{l}-0.003 \\
(4.58)\end{array}$ & $\begin{array}{l}0.000 \\
(0.19)\end{array}$ \\
\hline IY3 & 1 & -0.324 & -0.583 & -0.800 & $\begin{array}{l}-0.008 \\
(4.41)\end{array}$ & $\begin{array}{l}-0.004 \\
(4.46)\end{array}$ & $\begin{array}{l}0.001 \\
(1.06)\end{array}$ \\
\hline ND3 & 1 & -0.953 & -0.019 & -0.093 & -0.005 & 0.006 & 0.001 \\
& & & & & $(3.59)$ & $(4.42)$ & $(0.42)$ \\
\hline UK3 & 1 & -0.524 & 0.072 & -1.494 & $\begin{array}{l}0.000 \\
(0.03)\end{array}$ & $\begin{array}{l}0.002 \\
(3.94)\end{array}$ & $\begin{array}{l}-0.000 \\
(0.61)\end{array}$ \\
\hline & & & & & & & \\
\hline CA3 & 1 & - & -0.800 & -0.564 & -0.009 & - & -0.004 \\
& & & & & $(5.00)$ & & $(2.92)$ \\
\hline JA3 & 1 & - & -0.792 & -0.092 & -0.007 & - & -0.001 \\
& & & & & $(7.05)$ & & $(1.04)$ \\
\hline
\end{tabular}

The general tenor of the results contained in Table 3 may be summarized in the following way. Starting with the betas, we see that for all of the European countries there is a positive relationship between the home country interest rate and that for Germany, with the Netherlands having the highest point estimate and Italy the lowest. For all countries, apart from the UK, there is also a positive association between the home rate and the US rate, and it is interesting to note that for France and Italy this dominates the DM coefficient while for Belgium, Denmark and the Netherlands the DM coefficient dominates. It would seem, therefore, that even for a group of countries committed to European integration some of the countries have closer ties with the US than with Germany. It is perhaps surprising that the UK, which only had a half-hearted 
relationship with Europe during this period, appears to have a much stronger linkage with

Germany than with the US. For the two control countries - Canada and Japan - the $\beta$

coefficients on the US rate is larger than for any of the European countries. Note also that for the majority of interest rate combinations in Table 3 there is a constant positive wedge seperating the domestic rate from the linear combination of the German and US rates. We interpret this as a (constant) risk premium. Notice, however, that for two for the interest rate systems - Belgium and Denmark - this risk premium is actually negative suggesting that their rates could on average been lower than the sum of the German and US rates. This finding perhaps reflects the greater credibility with which these countries participated in the ERM. We explore the significance of these constant wedges below.

In terms of the adjustment coefficients in Table 3 (the $\alpha$ vector), we note that there is 'own' adjustment to the significant cointegrating vector in all of the systems, with the exception of the UK, where it appears that the DM rate is adjusting. The latter result perhaps reflects the importance of the UK as an independent financial center. Significant negative adjustment occurs in the home rate for the two control equations. We discuss the implications of these adjustment speeds for monetary independence below.

\subsection{Hypothesis Tests.}

We now attempt to push our interpretation of the results contained in Table 3 further by explicitly testing various hypotheses on the $\beta$ and $\alpha$ vectors. The different hypotheses tests, summarized in Table 4, are motivated by our discussion in Section 2. 
Table 4. Hypothesis Tests on $\beta$ and $\alpha$, where $x=\left[i^{o w n}, i^{g y 3}, i^{u s 3}, c o n\right]^{\prime}$

\begin{tabular}{|l|l|}
\hline $\mathrm{H} 1: \beta_{1}=0$ & $\mathrm{H} 5: \alpha_{3}=0$ \\
\hline $\mathrm{H} 2: \beta_{2}=0$ & $\mathrm{H} 6: \beta_{4}=0, \alpha_{3}=0$ \\
\hline $\mathrm{H} 3: \beta_{3}=0$ & $\mathrm{H} 7:[1,-1,0,0] \in \operatorname{Sp}(\beta), \alpha_{3}=0$ \\
\hline $\mathrm{H} 4: \beta_{4}=0$ & $\mathrm{H} 8:\left[1,-1,0,{ }^{*}\right] \in \operatorname{Sp}(\beta), \alpha_{3}=0$ \\
\hline
\end{tabular}

In sum, the hypotheses tests summarized in Table 4 involve sequentially testing zero restrictions in the long-run cointegrating relationships, testing whether the coefficients on the home and German interest rate can be restricted to a spread and, finally, testing for weak exogeneity of the US interest rate. The objective here is to discover what kind of interest parity relationship holds for the different pairings: is it a 'pure form' of interest parity, in which only the home and German interest rates enter as a spread?; is there a significant constant driving a wedge between these two rates?; and what role does the US interest rate play (does it explicitly enter the long run-relationship, or simply feature in the underlying dynamics)? In particular, we test eight hypotheses on each system and the hypothesis on $\beta$ may be most easily understood by referring to the following equation, which represents one of the normalized cointegrating vectors contained in Table 3.

$$
\beta_{1} i_{t}-\beta_{2} i_{t}^{g y}-\beta_{3} i_{t}^{u s}-\beta_{4}=0
$$

where $\beta_{1}$ is the coefficient on the own interest rate, $\beta_{2}$ is the coefficient on the German rate, $\beta_{3}$ is the coefficient on the US rate and $\beta_{4}$ is the constant. The subscripts on the $\alpha$ terms in Table 3 have the same assignments as the $\beta$ 's. 
Hypotheses $\mathrm{H}_{1}$ to $\mathrm{H}_{4}$ are tests for the long-run exclusion of the interest rates and the constant term from the cointegration space. More specifically, $\mathrm{H}_{1}$ tests for long-run exclusion of the 'home' or 'own' interest rate, $\mathrm{H}_{2}$ tests for the long-run exclusion of $\mathrm{GY} 3$, and $\mathrm{H}_{3}$ tests for the long-run exclusion of US3. $\mathrm{H}_{4}$ assesses if a constant is needed in the cointegration space. Clearly, if the constant term is significant in the long-run relationship this implies that we do not have a pure form of interest rate parity; the constant may be interpreted as a risk premium.

Hypothesis $\mathrm{H}_{5}$ tests for the weak exogeneity of the US interest rate (and therefore does not place any restrictions on the $\beta$ vector). If $\mathrm{H}_{5}$ is not rejected then it is possible to treat US3 as weakly exogeneous and the US rate may be interpreted as the exogenous variable driving the system. $\mathrm{H}_{6}$ tests for weak exogeneity of the US rate together with a zero restriction on the constant. Hypothesis $7, \mathrm{H}_{7}$, tests for the weak exogeneity of US3 together with the coefficient restriction that the cointegration vector is given by $(1,-1, *)$ (the asterisk indicates that no restriction is placed on the constant term). So $\mathrm{H}_{7}$ tests if US3 is a weakly exogenous variable driving a constant spread between bivariate ERM and GY interest rates. Hypothesis $\mathrm{H}_{8}$ is the most restrictive test and, relative to $\mathrm{H}_{7}$, places a zero restriction on the constant $(1,-1,0)$. If this hypothesis is not rejected the interpretation is that US3 is a weakly exogenous driving force behind the spread between ERM interest rates.

The estimated values of $\mathrm{H}_{1}$ to $\mathrm{H}_{4}$ are reported in Table 5a, while those of $\mathrm{H}_{5}$ to $\mathrm{H}_{8}$ are reported in Table 5b. The tests are linear Wald statistics, with an approximate chi-squared distribution indicated in brackets. The estimated p-value is recorded below the Wald test and numbers in bold type indicate that the null hypothesis is not rejected at the 5 per cent level; numbers not in bold type indicate that the null is rejected. 
Table 5a Estimated values of $\mathrm{H1}$ to $\mathrm{H4}$

\begin{tabular}{|c|c|c|c|c|}
\hline & H1 & H2 & H3 & H4 \\
\hline & \multicolumn{4}{|c|}{ Trivariate Systems } \\
\hline BM3 & $\begin{array}{l}\chi^{2}(1)=8.42 \\
p=0.0\end{array}$ & $\begin{array}{l}\chi^{2}(1)=5.99 \\
p=0.01\end{array}$ & $\begin{array}{l}\chi^{2}(1)=9.68 \\
p=0.0\end{array}$ & $\begin{array}{l}\chi^{2}(1)=4.24 \\
\mathrm{p}=0.04\end{array}$ \\
\hline DK3 & $\begin{array}{l}\chi^{2}(1)=7.51 \\
p=0.01\end{array}$ & $\begin{array}{l}\chi^{2}(1)=5.82 \\
p=0.02\end{array}$ & $\begin{array}{l}\chi^{2}(1)=3.94 \\
p=\mathbf{0 . 0 5}\end{array}$ & $\begin{array}{l}\chi^{2}(1)=0.09 \\
\mathrm{p}=\mathbf{0 . 7 6}\end{array}$ \\
\hline FE3 & $\begin{array}{l}\chi^{2}(1)=30.56 \\
p=0.0\end{array}$ & $\begin{array}{l}\chi^{2}(1)=7.17 \\
\mathrm{p}=0.01\end{array}$ & $\begin{array}{l}\chi^{2}(1)=28.5 \\
p=0\end{array}$ & $\begin{array}{l}\chi^{2}(1)=0.36 \\
\mathrm{p}=\mathbf{0 . 5 5}\end{array}$ \\
\hline IY3 & $\begin{array}{l}\chi^{2}(1)=31.04 \\
p=0.0\end{array}$ & $\begin{array}{l}\chi^{2}(1)=6.28 \\
p=0.01\end{array}$ & $\begin{array}{l}\chi^{2}(1)=31.72 \\
p=0.0\end{array}$ & $\begin{array}{l}\chi^{2}(1)=8.20 \\
\mathrm{p}=0.0\end{array}$ \\
\hline ND3 & $\begin{array}{l}\chi^{2}(1)=33.13 \\
p=0.0\end{array}$ & $\begin{array}{l}\chi^{2}(1)=33.52 \\
p=0.0\end{array}$ & $\begin{array}{l}\chi^{2}(1)=0.13 \\
\mathrm{p}=\mathbf{0 . 7 3}\end{array}$ & $\begin{array}{l}\chi^{2}(1)=0.42 \\
\mathrm{p}=\mathbf{0 . 5 2}\end{array}$ \\
\hline \multirow[t]{2}{*}{ UK3 } & $\begin{array}{l}\chi^{2}(1)=3.77 \\
\mathrm{p}=\mathbf{0 . 0 5}\end{array}$ & $\begin{array}{l}\chi^{2}(1)=3.06 \\
p=\mathbf{0 . 0 8}\end{array}$ & $\begin{array}{l}\chi^{2}(1)=0.05 \\
p=\mathbf{0 . 8 2}\end{array}$ & $\begin{array}{l}\chi^{2}(1)=3.93 \\
\mathrm{p}=\mathbf{0 . 0 5}\end{array}$ \\
\hline & \multicolumn{4}{|c|}{ Bivariate Systems } \\
\hline CA3 & $\begin{array}{l}\chi^{2}(1)=22.77 \\
p=0.0\end{array}$ & & $\begin{array}{l}\chi^{2}(1)=21.56 \\
p=0.0\end{array}$ & $\begin{array}{l}\chi^{2}(1)=7.74 \\
\mathrm{p}=0.01\end{array}$ \\
\hline JA3 & $\begin{array}{l}\chi^{2}(1)=41.02 \\
p=0.0\end{array}$ & & $\begin{array}{l}\chi^{2}(1)=39.74 \\
p=0.0\end{array}$ & $\begin{array}{l}\chi^{2}(1)=0.20 \\
\mathbf{p}=\mathbf{0 . 6 6}\end{array}$ \\
\hline
\end{tabular}

Table 5b. Estimated Values of H5 to H8

\begin{tabular}{|l|l|l|l|l|l|l|}
\hline & BM3 & DK3 & FE3 & IY3 & ND3 & UK3 \\
\hline H5 & $\chi^{2}(1)=1.13$ & $\chi^{2}(1)=2.09$ & $\chi^{2}(1)=0.03$ & $\chi^{2}(1)=1.16$ & $\chi^{2}(1)=0.14$ & $\chi^{2}(1)=0.24$ \\
& $\mathrm{p}=\mathbf{0 . 2 9}$ & $\mathrm{p}=\mathbf{0 . 1 5}$ & $\mathrm{p}=\mathbf{0 . 8 5}$ & $\mathrm{p}=\mathbf{0 . 2 8}$ & $\mathrm{p}=\mathbf{0 . 7 5}$ & $\mathrm{p}=\mathbf{0 . 6 2}$ \\
\hline H6 & $\chi^{2}(2)=4.29$ & $\chi^{2}(2)=2.13$ & $\chi^{2}(2)=0.51$ & $\chi^{2}(2)=11.0$ & $\chi^{2}(2)=0.79$ & $\chi^{2}(2)=4.63$ \\
& $\mathrm{p}=\mathbf{0 . 1 2}$ & $\mathrm{p}=\mathbf{0 . 3 4}$ & $\mathrm{p}=\mathbf{0 . 7 8}$ & $\mathrm{p}=0.0$ & $\mathrm{p}=\mathbf{0 . 6 7}$ & $\mathrm{p}=\mathbf{0 . 1 0}$ \\
\hline H7 & $\chi^{2}(2)=2.65$ & $\chi^{2}(2)=3.75$ & $\chi^{2}(2)=14.2$ & $\chi^{2}(2)=16.8$ & $\chi^{2}(2)=1.36$ & $\chi^{2}(2)=0.88$ \\
& $\mathrm{p}=\mathbf{0 . 2 7}$ & $\mathrm{p}=\mathbf{0 . 1 5}$ & $\mathrm{p}=0.0$ & $\mathrm{p}=0.0$ & $\mathrm{p}=\mathbf{0 . 5 1}$ & $\mathrm{p}=\mathbf{0 . 6 4}$ \\
\hline H8 & $\chi^{2}(3)=10.7$ & $\chi^{2}(3)=4.96$ & $\chi^{2}(3)=21.3$ & $\chi^{2}(3)=27.2$ & $\chi^{2}(3)=0.77$ & $\chi^{2}(3)=7.84$ \\
& $\mathrm{p}=0.01$ & $\mathrm{p}=\mathbf{0 . 1 7}$ & $\mathrm{p}=0.0$ & $\mathrm{p}=0.0$ & $\mathrm{p}=\mathbf{0 . 8 6}$ & $\mathrm{p}=\mathbf{0 . 0 5}$ \\
\hline
\end{tabular}

A test of weak-exogeneity in the bivariate system consisting of CA3 and JP3 is rejected $\left(\chi^{2}(1)=7.28, \mathrm{p}=0.01\right)$. 


\subsection{Results for the ERM countries}

Consider the results for the Belgian system, which are illustrative of the general testing procedure. We note that on the basis of $\mathrm{H} 1$ to $\mathrm{H} 3$ we cannot exclude any of the interest rates from the long-run relationship. The exclusion of the constant term from the cointegrating space is marginal (H4), although when this is combined with the weak exogeneity of the US interest rate (H6) the joint hypothesis cannot be rejected. Of more interest, perhaps, are the last two hypotheses in which we restrict the own-German interest rates to enter as a spread: H7 is clearly acceptable at the $5 \%$ level, while $\mathrm{H} 8$ is rejected. This means that we can restrict the long-run relationship for Belgium to have the following form:

$$
i_{t}^{B F}=i_{t}^{G Y}+\underset{(0.15)}{0.697 i_{t}^{U S}}-\underset{(0.31)}{1.146},
$$

where numbers in parenthesis are estimated standard errors. So there is a one-to-one lock between the Belgian and German interest rates, while the coefficient on the US rate is significantly less than unity. Confirming the result in Table 3 , we see that there is a negative constant wedge between Belgian, German and US interest rates for the full sample period and that this is statistically significant.

Referring back to Table 3 we note that only the Belgian rate adjusts significantly to the equilibrium error. The implied half-life for the Belgian interest rate is 230 days, which indicates the extent of monetary policy independence conferred by participation in the target zone. It is interesting to not that this half-life is slightly longer than that obtained by Bordo and MacDonald (1997) for the Classical gold standard period (a period which has been shown to be highly credible) 
How does the Belgian experience differ for countries with differing experiences in the ERM? For France, the restrictions tests reported in Table 5 indicate that the only two hypotheses that cannot be rejected are $\mathrm{H} 4$, which has only the constant restricted to zero, and H6 where the restriction on the constant and the weak exogeneity of the US rate goes through. This means that the long-run French relationship has the following form:

$$
i_{t}^{F F}=\underset{(0.09)}{0.468 i_{t}^{G Y}}+\underset{(0.08)}{0.700 i_{t}^{U S}},
$$

It is quite striking that the coefficient on the German interest rate is both significantly less than unity and also that it is almost half the magnitude of the coefficient on the US rate. Of course, the fact that there is such a large wedge between the two rates may be explicable in terms of the number of currency realignments that took place during this period. As in the Belgian system, adjustment to equilibrium takes place both through the 'own' and German rates; however, here both $\alpha$ terms are significant. The half-life for the French system is approximately half that of the Belgian system indicating, perhaps, that the lesser commitment of the Banque de France to the ERM during much of this period gave it less policy independence (because of the lack of credibility).

The contrast between the French results and those for the Netherlands is quite striking. The Dutch central bank probably had the strongest commitment to the ERM during our sample (particularly for the latter half of the period) and this seems to be borne out by the hypothesis tests reported in Table 5. Not only can the cointegrating vector be restricted to [1, -1] for NG3 and DM3 but the US rate is weakly exogenous (H6) and indeed can even be excluded completely from the long-run space $(\mathrm{H} 7)$. This would seem to indicate that the US rate is not needed in the 
Dutch system. A simple bivariate model consisting of just the Dutch and German rates produces a single significant cointegrating vector. This vector can be restricted to a strict form of interest parity:

$$
i_{t}^{N G}=i_{t}^{G Y},
$$

The estimated value of the $\operatorname{LR}(2)$ test, which tests the restrictions imposed in (11) is 3.77, with a p-value of 0.15. The alpha values associated with (11) are $-0.004(3.57)$, for $\Delta i_{t}^{N G}$ and $0.005(4.07)$ for the $\Delta i_{t}{ }^{G Y}$ equation. Therefore only the home rate adjusts towards equilibrium in this system and the half-life is the same as that in the Belgian system. Thus the two countries which had a similar commitment to the ERM had similar degrees of freedom in their monetary policy decision making. It is interesting that this freedom is clearly greater than for partner countries (such as France and Italy) which perhaps had a lesser commitment to the system.

Summarizing the remaining long-run results contained in Tables 3 and 5, we see that the Italian system has properties which are similar to the French system - non-homogeneity in the long-run relationship and an adjustment speed which suggests a similar half-life. The Danish system (Table 7) is much closer to the Belgian and Dutch systems, with homogeneity holding and the adjustment speeds being similar as well. The results for the British system (Table 8) are interesting since they produce long-run interest rate homogeneity for the period, but there is no adjustment towards equilibrium for the home interest rate.

In a bid to determine if the existence of the significant constants are sample- specific we recomputed hypothesis test $\mathrm{H} 4$ for Belgium, Italy and the UK (the 3 countries with significant wedges in Table 4), using the sample period January 1987 to the last observation in December 1991. This sample encompasses a period in which the ERM was at its most tranquil and 
therefore should be the period most likely to produce a zero risk premium. The results indicate that for two of the countries - Italy and the UK - the significant wedge disappears. However, for Belgium the significance of the wedge seems to have increased for this sub-period since the pvalue has dropped from 0.04 to 0.00 . The results for Italy and even the UK (which initially shadowed the mark and then was a full participant of the ERM during this period) seem intuitively plausible. The results for Belgium are perhaps more puzzling given that its central bank was closely aligned to the Bundesbank's monetary policy during this period.

\begin{tabular}{|c|c|}
\hline \multicolumn{2}{|c|}{$\begin{array}{l}\text { Estimated values of } \mathrm{H} 1 \text { to } \mathrm{H} 4 \\
\text { for sub-sample } 1987 \text { to } 1991 \text {. }\end{array}$} \\
\hline & H4 \\
\hline BM3 & $\begin{array}{l}\chi^{2}(1)=13.93 \\
p=0.00\end{array}$ \\
\hline IY3 & $\begin{array}{l}\chi^{2}(1)=2.50 \\
p=\mathbf{0 . 1 1}\end{array}$ \\
\hline UK3 & $\begin{array}{l}\chi^{2}(1)=0.25 \\
p=0.62\end{array}$ \\
\hline
\end{tabular}

\subsection{Results for Canada and Japan.}

The results for the two control systems, namely Canada-US and Japan-US, are reported in the bottom half of Table 3 and in Table $5 \mathrm{~b}$. The Canadian-US system produces one statistically significant cointegrating relationship. However, we are unable to restrict the cointegrating space using any of the hypothesis considered for the ERM countries. The unrestricted vector has the following form:

$$
i_{t}^{C A}=\underset{(0.06)}{0.80 i_{t}^{U S}}+\underset{(0.13)}{0.56},
$$

which indicates that Canadian short rates are permanently above US rates by a constant factor of 0.56 (this follows from the restrictions tests, although we should add in standard errors to 
reinforce the point). Further, there would also seem to be long-run policy independence for Canada in the sense that there is not a one-to-one lock between Canadian and US interest rates. The contrast between this result and those obtained for the ERM interest rates presumably reflects the fact that the Canadian dollar was not involved in a target zone arrangement during this sample period. We also note that both rates adjust to the disequilbrium, although the largest adjustment occurs through the Canadian rate.

The Japanese-US system also produces clear evidence of a single cointegrating vector and, in contrast to the Canadian system, this can be restricted so that the US rate is weakly exogenous and the constant is zero. The restricted long-run relationship has the following form:

$$
i_{t}^{J P}=\underset{(0.08)}{0.839} i_{t}^{U S}
$$

As in the Canadian interest rate relationship, this equation also has the feature that there is not a proportional relationship between the Japanese and US short rates, again reflecting the fact that the Japanese yen was not involved in a target zone arrangement during this period. Perhaps this result is less surprising for Japan since the country is less likely to approximate a small open economy than Canada. The alpha matrix indicates that there is significant adjustment by Japanese rates to the disequilibrium between Japanese and US interest rates although this adjustment is faster than that found for the most 'credible' ERM countries.

\section{The Orthogonal Directions.}

As a final perspective on the interactions among the interest rates in each of our systems, we examine the orthogonal complements to $\alpha$ and $\beta$, denoted $\alpha \perp$ and $\beta \perp$, obtained from (5'). The $\alpha \perp$ for each of our systems is reported in Table 6 , while the $\beta_{\perp}$ terms are recorded in Table 7 . The 
$\alpha \perp_{\perp}{ }^{1}$ and $\alpha_{\perp}{ }^{2}$ terms represent the two common trends in each of the interest rate systems: with three non-stationary interest rates in each system and one cointegrating vector there are two common trends. For DK3, FF3 and IY3 there is a common pattern since the dominant factor driving the first common trend in each case is DM3 while it is US3 which is the dominant variable driving the second common factor. In contrast, for BM3, NG3 and UK3 it is US3 which is the main driving force for the first common trend and in the case of the Netherlands and the UK it is the 'own' rate which is the main driving force for the second common trend.

Table 6 The Alpha Orthogonal Components.

\begin{tabular}{|l|l|l|l|l|l|l|l|l|}
\hline & $\alpha \perp^{1}$ & & & & $\alpha \perp^{2}$ & & & \\
\hline & OWN & GY3 & US3 & & OWN & GY3 & US3 & \\
\hline BM3 & -0.248 & -0.084 & -0.965 & & 0.352 & -0.936 & -0.009 & \\
\hline DK3 & 0.066 & -0.995 & -0.079 & & -0.210 & 0.063 & -0.976 & \\
\hline FF3 & 0.397 & -0.918 & 0.004 & & 0.006 & -0.001 & -1.00 & \\
\hline IY3 & 0.469 & -0.875 & 0.115 & & -0.050 & -0.156 & -0.987 & \\
\hline NG3 & -0.099 & -0.183 & 0.978 & & 0.777 & 0.600 & 0.191 & \\
\hline UK3 & -0.005 & -0.173 & -0.984 & & 0.999 & -0.0112 & -0.0038 & \\
\hline
\end{tabular}

Turning to Table 7, for DK3, FF3 and IY3 the first common factor, which as we have seem is predominantly driven by the German interest rate, has it greatest loading in the $\Delta \mathrm{GY} 3$ equation, although it also gets a relatively large loading into both own rates in DK3 and FF3. For these three countries the second common factor has its greatest loading in the $\Delta \mathrm{US} 3$ equation, although 
the loading of this common factor into the own equation is also important. For the Netherlands and the UK, the first common factor (driven by US for them) gets the greatest loading in the US equation while the second gets an equal weighting in both the own and German equations. For Belgium both the first and second common factors get about equal weighting in the own and GY3 equations.

Table 7 The Beta Orthogonal Components

\begin{tabular}{|l|l|l|l|l|l|l|l|l|}
\hline & $\beta_{\perp}{ }^{1}$ & & & & & & & \\
& $\Delta$ OWN & $\Delta \mathrm{DM} 3$ & $\Delta \mathrm{US} 3$ & & $\Delta \mathrm{OWN}$ & $\Delta \mathrm{DM} 3$ & $\Delta \mathrm{US3}$ & \\
\hline BM3 & -0.890 & -0.345 & -0.854 & & -0.949 & -1.484 & 0.384 & \\
\hline DK3 & -0.784 & -1.132 & 0.164 & & -0.517 & 0.027 & -0.952 & \\
\hline FF3 & -0.553 & -1.357 & -0.009 & & -0.922 & -0.439 & -1.119 & \\
\hline IY3 & -0.272 & -1.322 & 0.226 & & -0.760 & -0.586 & -0.972 & \\
\hline NG3 & -0.158 & -0.187 & 1.085 & & 0.860 & 0.897 & 0.226 & \\
\hline UK3 & -0.012 & -0.172 & -1.097 & & 0.998 & 1.853 & -0.372 & \\
\hline
\end{tabular}

In sum, the analysis of the orthogonal complements to alpha and beta essentially confirms the findings from the conventional (i.e. non-orthogonal) analysis: both German and US rates are important for the determination of the group of six European rates considered here, although there are two distinct sub-groupings of rates, with the Danish, French and Italian rates having a German focus and the remaining rates having a more mixed composition. 
Table 8. Estimates of the Long-run Impact Matrix, C.

\begin{tabular}{|l|l|l|l|}
\hline & $\Sigma \varepsilon_{\text {own }}$ & $\Sigma \varepsilon_{\mathrm{gy} 3}$ & $\Sigma \varepsilon_{\mathrm{us} 3}$ \\
\hline BM3 & $-0.114(0.32)$ & $0.963(3.38)$ & $0.867(3.22)$ \\
\hline GY3 & $-0.437(1.17)$ & $1.418(4.78)$ & $0.346(1.23)$ \\
\hline US3 & $0.346(1.49)$ & $-0.287(1.56)$ & $0.821(4.71)$ \\
\hline & & & \\
\hline DK3 & $0.057(0.47)$ & $0.747(5.81)$ & $0.566(5.38)$ \\
\hline GY3 & $-0.080(0.64)$ & $1.128(8.46)$ & $0.063(0.58)$ \\
\hline US3 & $0.211(1.70)$ & $-0.223(1.68)$ & $0.916(8.47)$ \\
\hline & & & \\
\hline FF3 & $-0.226(1.58)$ & $0.509(7.96)$ & $0.920(8.18)$ \\
\hline GY3 & $-0.542(2.74)$ & $1.246(14.05)$ & $0.434(2.78)$ \\
\hline US3 & $-0.011(0.08)$ & $0.009(0.15)$ & $1.119(10.63)$ \\
\hline & & & \\
\hline IY3 & $-0.090(0.74)$ & $0.356(7.17)$ & $0.718(7.95)$ \\
\hline GY3 & $-0.592(2.62)$ & $1.249(13.54)$ & $0.426(2.54)$ \\
\hline US3 & $0.155(1.04)$ & $-0.047(0.77)$ & $0.985(8.92)$ \\
\hline & & & \\
\hline NG3 & $0.683(4.61)$ & $0.544(5.18)$ & $0.010(0.41)$ \\
\hline GY3 & $0.716(4.63)$ & $0.572(5.23)$ & $-0.012(0.46)$ \\
\hline US3 & $0.067(0.36)$ & $-0.063(0.47)$ & $1.104(35.29)$ \\
\hline & & & \\
\hline UK3 & $0.998(2.05)$ & $-0.009(0.03)$ & $0.008(0.16)$ \\
\hline GY3 & $(2.01)$ & $(0.02)$ & $(1.82)$ \\
\hline US3 & $-0.366(0.64)$ & $0.195(0.61)$ & $1.082(19.74)$ \\
\hline
\end{tabular}

In Table 8 we report our estimates of the long run impact matrix, $\mathrm{C}$, derived from expression $\left(5^{\prime}\right)$. In particular, we show the cumulative impact of a unitary change in the shocks derived from each of the interest rate relationships - the home, $\varepsilon_{\text {own }}$, the German, $\varepsilon_{\mathrm{gy} 3}$, and the US, $\varepsilon_{\text {us3 }}$. The column headings in Table 8 show the source of the shocks, while the rows show the impact they have on the different interest rate systems. The first three rows contain the Belgian system, and so on. These results clearly demonstrate the importance of the shock to German interest rates to all of the own rates, apart from the UK. Not surprisingly, the German shocks 
also have significant own effects in all of the systems again apart from the UK. The cumulative impact of US interest rate shocks is also significant in all of the systems apart from the UK and the Netherlands. The latter result confirms our earlier finding that the US could be excluded from the Dutch interest rate system. The only two systems for which the home rate has a significant own effect is in the Dutch and UK systems.

\section{Summary and Conclusions.}

In this paper we have attempted to quantify the degree of monetary independence for a group of countries participating in the ERM of the EMS. Our motivation was Svensson (1994) who argues that the credibility of a target zone will crucially determine the extent of monetary independence. As a target zone experience, the ERM is known to have a lesser degree of absolute credibility than the Classical gold standard period. However, although the system may have been non-credible in absolute terms, there were some important relative credibility effects both across time and also across countries. This paper has sought to focus on the latter element, although the relative time credibility has also been touched upon.

As in Bordo and MacDonald (1997), we use an interest parity arbitrage condition as the main focus of our work. In particular, if a target zone system is credible then, on average, uncovered interest parity should hold exactly. Given the potential non-stationarity of the variables we test this proposition using the cointegration framework of Johansen. This framework has the added advantage that a number of hypotheses regarding both the long- and short-run behavior of the different systems may be tested. For example, we tested if the coefficient in the foreign interest rate is insignificantly different from unity, if the constant is 
significantly different from zero or not and which of the rates adjusts to the long-run disequilibrium.

We summarize our results for the ERM-based systems in the following way. First, simply considering bivariate pairings of a domestic and German interest rate was not sufficient to produce a significant cointegrating vector. However, when a US rate with a comparable maturity was introduced into each system this produced a unique cointegrating vector in each case. We interpret the importance of the US rate as indicative that the US still provides the central axis for the determination of international interest rate policy, despite the fact that all but one of the central banks considered here were actively trying to converge on German monetary policy for much of this period. We find that there are essentially two groups of countries. In the case of Belgium, Denmark and the Netherlands we are able to restrict the coefficient on the German rate to be unity and, additionally, the constant may be restricted to zero in the Danish and Dutch cases. Indeed, the system for the Netherlands may be reduced to the most restrictive system of all in which the US rate is also excluded from the long-run cointegrating space, leaving only a tight one-to-one lock between the Dutch and German rates. The experience of France and Italy is different in the sense that there is not degree one homogeneity between domestic and German interest rates, even when the US rate is included, and also the adjustment speeds to disequilibrium are much slower for these interest rate systems. These rates therefore form a second grouping which we interpret as a less credible grouping and one in which convergence was still taking place during our sample period. On the periphery is the UK, which exhibits properties which straddle the two groups: it has a unitary coefficient on the German interest rate, 
but adjustment to disequilibrium occurs through the German rate rather than the own rate which has a coefficient of effectively zero.

The results in this paper seem to validate the central prediction of the Svennson model. Countries that adopt credible monetary policies will have some leeway to pursue an independent monetary policy, even with fixed exchange rates. Our calculation on the extent of this independence is around one and a half years for a reasonably credible country like the Netherlands. Although this, of course, probably does not offer countries sufficient monetary independence to engage in traditional demand management policies, it does suggest that the time horizon is important when considering the 'unholy trinity' of perfect capital mobility, fixed exchange rates and an independent monetary policy. 


\section{References}

Anthony, Myrvin. and Ronald MacDonald (1998), "On the mean-reverting properties of the target zone exchange rates: Some evidence from the ERM", European Economic Review 42, 1493-1523.

Bordo, Michael D. and Ronald MacDonald (1997) "Violations of the 'Rules of the Game' and the Credibility of the Classical Gold Standard, 1880-1914". NBER Working Paper No. 6115. July.

Campbell, John and Pierre Perron (1991) "Pitfalls and Opportunities: What Macroeconomists Should Know About Unit Roots”, NBER Macroeconomics Manual, Vol 6, 141-220.

Cheung, Yin-Wong and Kon Lai (1993), "Finite Sample sizes of Johansen Likelihood ratio tests for cointegration", Oxford Bulletin of Economics and Statistics, 55: 313-28.

De Grauwe, Paul (1989), 'Is the European Monetary System a DM-zone?', CEPR, Discussion paper No 297, March.

Doornik John and Henrik Hansen, 1994, DA Practical Test of Multivariate Normality, $]$ unpublished paper, (Oxford: Nuffield College).

Edison, Hali and Linda Kole (1995), 'European Monetary Arrangements: Implications for the Dollar, exchange rate and credibility', European Financial Management, 1, 61-86.

Engle, Robert and Clive Granger (1987), "Cointegration and Error Correction: Representation, Estimation and Testing", Econometrica, 55, 251-76.

Godfrey, L.G., 1988, Misspecification Tests in Econometrics, (Cambridge, Mass.: Cambridge University Press).

Hallwood, Paul, Ronald MacDonald and Ian W. Marsh (1997a), "Credibility and Fundamentals: Were the Classical and Inter-War Gold Standards well-behaved Target Zones?", in Modern Perspectives on the Gold Standard, T. Bayoumi, B. Eichengreen and M.P. Taylor, Cambridge: Cambridge University Press.

Hendry, David and Graham Mizon (1993), “Evaluating Dynamic Econometric Models by Encompassing the VAR", in P.C.B. Phillips (ed), Models, Methods and Applications of Econometrics, 272-300, Oxford: Blackwell.

Johansen, Soren (1988), "Statistical Analysis of Cointegrating Vectors", Journal of Economic Dynamics and Control, 2, 7-46. 
Johansen, Soren, 1995, Likelihood ПBased Inference in Cointegrated Vector Autoregressive Models, (Oxford: Oxford University Press).

Officer, L.H. (1996), Between the Dollar-Sterling Gold Points: Exchange Rates, Parity and Market Behavior. Cambridge: Cambridge University Press.

Osterwald-Lenum, M. (1993), "Recalculated and Extended Tables of Asymptotic Distribution of Some Important Maximum Likelihood Cointegrating Test Statistics, Oxford Bulletin of Economics and Statistics,

Rose, Andrew and Lars Svensson (1994), "European Credibility Before the Fall”, European Economic Review, 38, 1185-1223.

Svensson, Lars E. O. (1994) “Why Exchange Rate Bands?” Journal of Monetary Economics. 33. pp. $157-199$.

von Hagen, Jurgen and Michelle Fratianni (1990), 'German Dominance in the EMS: Evidence from Interest Rates', Journal of International Money and Finance, Vol9, 387-375.

Weber, Axel (1990), 'EMU and Asymmetries and adjustment problems in the EMS: Some Empirical Evidence', CEPR Discussion paper No 448, August. 
Figure 1. German and US Interest Rates Relative to 'Own' Rate

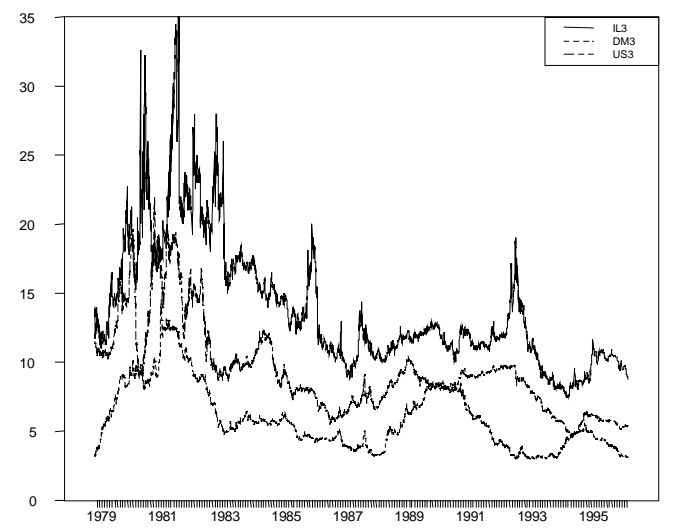

Italy 3 Month

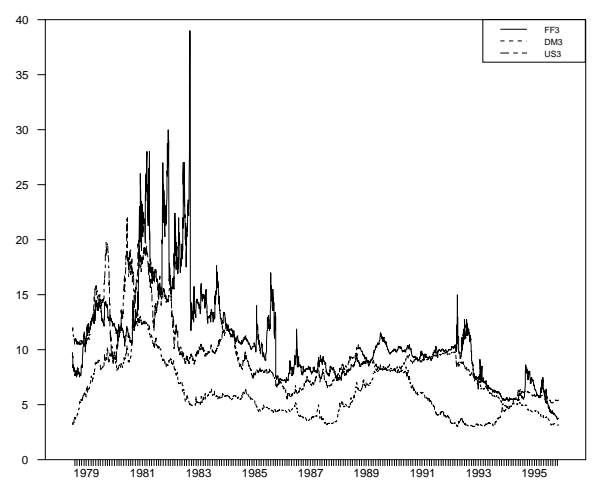

France 3 Month



Denmark 3 Month 
Figure 1 Contd.

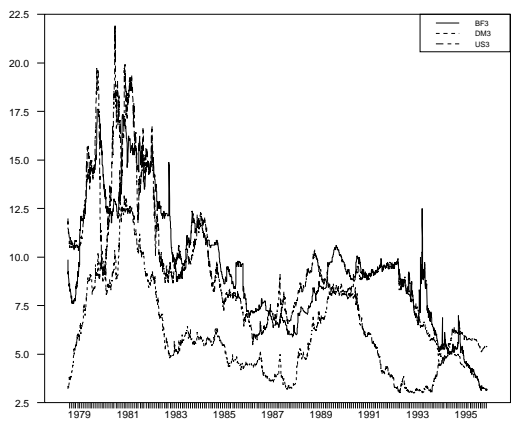

Belgium 3 Month

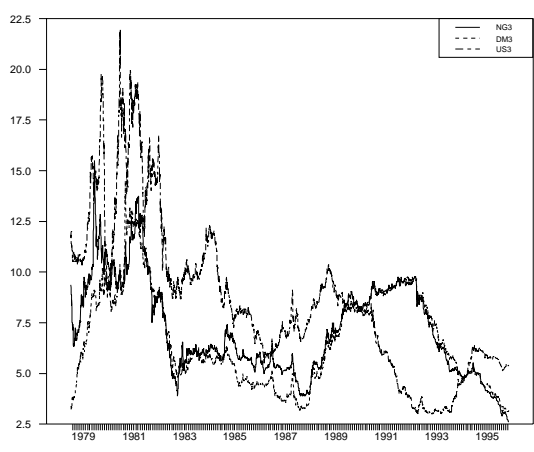

Netherlands 3 Month:

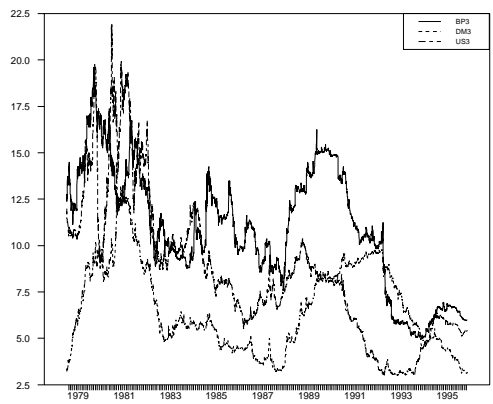

UK3 Month 
Figure 1 Contd.

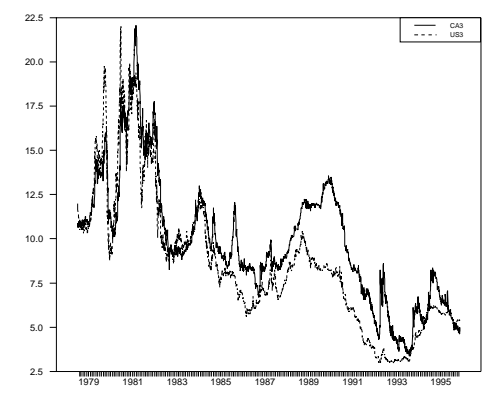

Canada 3 Month

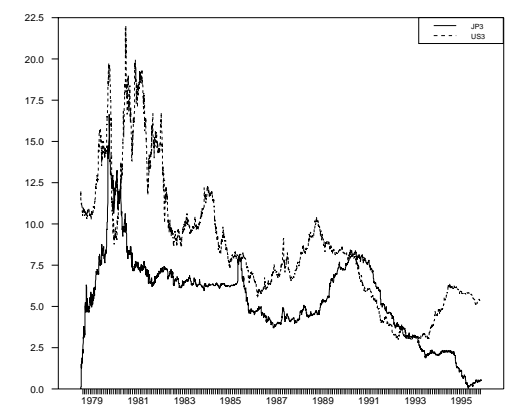

Japan 3 Month 